\title{
EMPIRICAL VALIDATION OF AN E-LEARNING COURSEWARE USABILITY MODEL
}

\author{
Alex Koohang, Middle Georgia State College, USA, alex.koohang@mga.edu \\ Joanna Paliszkiewicz, WarsawUniversity of Life Sciences, Poland,joanna_paliszkiewicz@sggw.pl
}

\begin{abstract}
The purpose of this study was to empirically validate an e-learning courseware usability model, which consisted of three usability components: fundamental, appearance, and information presentation. Each component was comprised of a number of factors/usability properties essential to the design of usability of an e-learning courseware. Data from 119 subjects, taking online courses, were analyzed using Factor Analysis. The results of the study revealed that the three components of the instrument were empirically validated to be reliable and interpretable among their associated factors. Conclusions and recommendations are made based on the findings.
\end{abstract}

Keywords: E-learning, courseware, usability, usability model

\section{INTRODUCTION}

A study by Allen and Seaman (2014) noted that the popularity of e-learning is souring rapidly. Over 7 million higher education students are taking at least one online course and this number is growing every year. Today, there are more academic leaders favoring e-learning than in the past years. In fact, they rate the learning outcomes of the distance education as comparable (and often superior) to those in face-to-face classes (Allem \& Seaman, 2014).

The delivery of instructional content is normally accomplished using a courseware, also known as a platform or a learning management system (LMS). Koohang (2004a, 2004b) asserted that a critical success factor in successful elearning instructional design is the usability of the e-learning courseware.

Usability, in general, is the ability of a system or a product to effectively and efficiently meet the user needs and specifications leading to user satisfaction and user adoption (c.f. Koohang, 2004a). Keinonen $(1998,62)$ asserted that usability characteristics are related to "1) the product's design process, 2) the product itself, 3) use of the product, 4) user experiences of the product or 5) user expectations." ISO 9126 (1991) defined usability as "a set of attributes that bear on the effort needed for use, and on the individual assessment of such use, by a stated or implied set of user". Shackel (1991) asserted that "usability of a system or equipment is the capability in human functional terms to be used easily and effectively by the specified range of users, given specified training and user support, to fulfill the specified range of tasks, within the specified range of environmental scenarios". Caplan (1994) asserted that usability was a critical aspect of system/software design. The author defined usability as the user comfort that is experienced using a system or a product.

In general, usability of a system or a product is the measure of the quality of the experience users acquire (Rubin, 1994; Rosenbaum, 1989; Guillemette, 1989; Dumas \& Redish, 1993; Shackel 1991; Nielsen 1993; Nielsen, 2000). The successful outcome of the quality of the user's experience with a system or a product depends on the usability attributes.

Shackel (1991) defined the usability attributes as effectiveness, learnability, flexibility, and attitude. Nielsen (1993) referred to usability attributes as learnability, efficiency, memorability, error, and satisfaction. In 1998, ISO 924111 (1998) asserted that usability attributes are effectiveness, efficiency, and satisfaction. Subsequently, in 2001, ISO 9126 (2001) modified these attributes to understandability, learnability, operability, attractiveness, and usability compliance. Furthermore, Quesenbery (2003) listed the "five E's of usability": 1) effectiveness, 2) efficiency, 3 ) engagement, 4 ) error and tolerance, and 5 ) ease of learning".

The attainment of the usability attributes depends on usability properties, i.e., ease of use, simplicity, navigability, etc. These properties must be designed and built into the system for achieving usability (Rubin, 1994; Rosenbaum, 
E-learning courseware can be delineated as a web-based course management system or platform that allows the design, development of creative activity, and delivery of e-learning courses through the Internet (Koohang, 2004a). Usability of e-learning courseware refers to various things such as the platform specifications, cover layout, the navigational systems and construction, the aesthetic qualities, and the qualities that promote user-friendliness (Koohang \& du Plessis, 2004); therefore, contributing to user satisfaction and user acceptance that positively influences the learning process (Koohang \& du Plessis, 2004; Koohang, 2004a). E-learning courseware usability is important because it functions as the major stream to the instructional concept (Koohang, 2004a; Koohang, 2004b; Koohang \& du Plessis 2004; Koohang, 2012).

\section{E-LEARNING COURSEWARE USABILITY MODEL}

The e-learning courseware usability model that is advanced by the authors of the present study is based on a stream of research on courseware usability (Koohang, 2004a; Koohang, 2004b; Koohang \& du Plessis 2004). The model consists of three components. They are fundamental, appearance, and information presentation. Each component embraces a number of associated usability properties describing its affluence. The associated usability properties for each component in the model are as follows:

\section{E-Learning Courseware Usability - Fundamental Component}

The fundamental component is the basis for e-learning courseware usability, which helps users with efficiency, satisfaction, and learnability. This component includes six usability properties. They are:

1. Simplicity: The e-learning courseware should be simple, uncomplicated, and straightforward.

2. Comfort: Users must be comfortable using the e-learning courseware.

3. User friendly: The e-learning courseware should be easy to use.

4. Control: Users should be in control of what they are doing when using the e-learning courseware.

5. Navigability: Users should easily navigate and get to where they want to go when using the e-learning courseware.

6. Load time: Pages should load quickly in the e-learning courseware.

\section{E-Learning Courseware Usability - Appearance Component}

The appearance component helps users with memorability, error, and learnability. The usability properties of this component include the following:

1. Recognition: Users quickly identify the key points presented for carrying out tasks when they use elearning courseware.

2. Visual appearance: The visual appearance (text boldfacing, italicizing, underlining, font size, link visibility) is present throughout the e-learning courseware.

3. Consistency: Consistency of appearance, terms, words, and action are present throughout the e-learning courseware.

4. Well-organized: The pages are well-organized and structured in the e-learning courseware.

\section{E-Learning Courseware Usability - Information Presentation Component}

The information presentation component assists users with efficiency, memorability, error, and learnability. It includes four usability properties. They are:

1. Understandability: The information in the e-learning courseware is understandable and easy to read.

2. Relevancy: The information presented in the e-learning courseware is relevant to what users need to know.

3. Adequacy: The information presented in the e-learning courseware is no more/no less than what users need to know.

4. Right to the point: The information in the e-learning courseware is concise and right to the point. 
The model contends that all components are interrelated. They are critical to e-learning courseware usability and must be present, with their associated factors, in the design of e-learning courseware usability.

\section{PURPOSE OF THE STUDY}

The purpose of this study was to empirically validate our e-learning courseware usability model. Based on the study's purpose, three research questions were advanced:

RQ1: Is the fundamental component of the instrument empirically validated to be reliable and interpretable among its six usability properties: 1) simplicity, 2) comfort, 3) user friendly, 4) control, 5) navigability, and 6) load time?

RQ2: Is the appearance component of the instrument empirically validated to be reliable and interpretable among its four usability properties: 1) recognition, 2) visual appearance, 3) consistency, and 4) wellorganized?

RQ3: Is the information presentation component of the instrument empirically validated to be reliable and interpretable among its four usability properties: 1) understandability, 2) relevancy, 3) adequacy/task match, and 4) right to the point?

\section{METHODOLOGY}

\section{Instrument}

The instrument for this study was designed based on our e-learning courseware usability model. The instrument consists of 14 items divided into three components (fundamental, appearance, and information presentation) that describe the usability of e-learning courseware. Each component included a number of usability properties describing the component. The items of the instrument were as follows:

1. The e-learning courseware is simple, uncomplicated, and straightforward.

2. I am comfortable using the e-learning courseware.

3. The e-learning courseware is easy to use.

4. I feel I am in control of what I am doing when I use the e-learning courseware.

5. Using the e-learning courseware, I can easily navigate and get to where I want to go.

6. Pages load quickly in the e-learning courseware.

7. I quickly identify the key points presented for carrying out tasks when I use the e-learning courseware.

8. The visual appearance (text boldfacing, italicizing, underlining, font size, link visibility) is present throughout the e-learning courseware.

9. I notice the consistency of appearance, terms, words, and action throughout the e-learning courseware.

10. The pages are well-organized and structured in the e-learning courseware.

11. The information in the e-learning courseware is understandable and easy to read.

12. The information presented in the e-learning courseware is relevant to what I need to know.

13. The information presented in the e-learning courseware is no more/no less than what I need to know.

14. The information in the e-learning courseware is concise and right to the point.

Items 1 - 6 represented the usability properties for the fundamental component. Items $7-10$ represented the usability properties for the appearance component. Items $11-14$ represented the usability properties for the information presentation component. The instrument used a Likert-type scale with the following scoring strategy: strongly agree $=5$, agree $=4$, neither agree nor disagree $=3$, disagree $=2$, and strongly disagree $=1$.

\section{Procedure and Participants}

This study took place in a higher education institution located in the Southeast USA. After obtaining approval from the Institutional Research Board (IRB), the instrument was administered electronically to 123 subjects who were studying in an undergraduate information technology online program. Four of the 123 collected data were incomplete, yielding 119 total usable data for the study. The subjects were male (53\%) and female (47\%) ranging 


\title{
Issues in Information Systems
}

Volume 15, Issue II, pp. 270-275, 2014

from 18 to over 40 years of age. The subjects were guaranteed confidentiality and assured that their responses would be kept confidential.

\section{Data Analyses}

Collected data were analyses via SPSS, a statistical analysis software. Kaiser criterion procedure was conducted to determine the number of factors that could be retained. This procedure retains only factors with eigenvalues greater than 1 as common factors and eliminates the factors with eigenvalues less than 1 . Next, the scree test, a graphical representation of the eigenvalues, that uses principal component analysis was conducted to ascertain data points above the break point where the number of factors that are retained. Subsequently, principal component analysis with varimax rotation was conducted to force the number of components with their associated factors that could be retained. Finally, Cronbach alpha procedures were conducted to determine internal consistency among the factors for each component.

\section{RESULTS}

Kaiser criterion revealed three factors with eigenvalues greater than 1 that could be retained. These factors, therefore, were included in factor analysis using principal components analysis. (See Table 1)

Table 1: Total Variance Explained

\begin{tabular}{|c|c|c|c|}
\hline \multirow{2}{*}{ Component } & \multicolumn{3}{|c|}{ Rotation Sums of Squared Loadings } \\
\cline { 2 - 4 } & Total & \% of Variance & Cumulative \% \\
\hline 1 & 3.777 & 26.978 & 26.978 \\
\hline 2 & 2.888 & 20.630 & 47.609 \\
\hline 3 & 2.748 & 19.629 & 67.238 \\
\hline
\end{tabular}

Extraction Method: Principal Component Analysis

Furthermore, the scree test using principal component analysis acknowledged the data points above the break and indicated three factors to be retained. The principal component analysis with varimax rotation forced three components, with their associated factors, to be retained. (See Table 2)

Component 1 retained factors $1,2,3,4,5$, and 6 , which represented the fundamental properties in the model. The factors are:

\author{
Factor 1 - Simplicity \\ Factor 2 - Comfort \\ Factor 3 - User friendly \\ Factor 4 - Control \\ Factor 5 - Navigability \\ Factor 6 - Load time
}

Component 2 retained factors $7,8,9$, and 10, which represented the appearance properties in the model. The factors are:
Factor 7 - Recognition
Factor 8 - Visual appearance
Factor 9 - Consistency
Factor 10 - Well-organized

Component 3 retained factors 11,12,13, and 14, which represented the information presentation Properties in the model. The factors are:

Factor 11 - Understandability

Factor 12 - Relevancy

Factor 13 - Adequacy/task match

Factor 14 - Right to the point 
Table 2: Rotated Component Matrix - Varimax with Reliability Analysis

\begin{tabular}{|l|l|l|l|}
\hline \multirow{2}{*}{$\begin{array}{l}\text { E-Learning Courseware Usability } \\
\text { Components }\end{array}$} & \multicolumn{3}{|c|}{ Component } \\
\hline $\begin{array}{l}\text { Fundamental Component's Usability } \\
\text { Properties }\end{array}$ & & & \\
\hline Simplicity & $\mathbf{. 7 5 2}$ & & \\
\hline Comfort & $\mathbf{. 7 2 4}$ & & \\
\hline User friendly & $\mathbf{. 7 8 9}$ & & \\
\hline Control & $\mathbf{. 7 5 3}$ & & \\
\hline Navigability & $\mathbf{. 8 3 2}$ & & \\
\hline Load time & $\mathbf{. 6 1 9}$ & & \\
\hline $\begin{array}{l}\text { Appearance Component's Usability } \\
\text { Properties }\end{array}$ & & & \\
\hline Recognition & & $\mathbf{. 8 6 3}$ & \\
\hline Visual appearance & & $\mathbf{. 8 8 9}$ & \\
\hline Consistency & & $\mathbf{. 8 7 1}$ & \\
\hline Well-organized & & $\mathbf{. 5 2 5}$ & \\
\hline Information Presentation Component's & & & \\
\hline Usability Properties & & & \\
\hline Understandability & & & $\mathbf{. 8 2 0}$ \\
\hline Relevancy & & & $\mathbf{. 7 5 2}$ \\
\hline Adequacy/task match & & & $\mathbf{. 7 3 6}$ \\
\hline Right to the point & & & $\mathbf{. 5 5 5}$ \\
\hline & & & \\
\hline Cronbach's Alpha & $\mathbf{. 8 7 8}$ & $\mathbf{. 8 0 3}$ & $\mathbf{. 8 6 0}$ \\
\hline
\end{tabular}

\section{CONCLUSIONS}

This study advanced and validated an e-learning usability model. The model consisted of three components with their associated usability properties: fundamental component (simplicity, comfort, user friendly, control, navigability, and load time); appearance component (recognition, visual appearance, consistency, and wellorganized); and information presentation component (understandability, relevancy, adequacy/task match, and right to the point). The model asserted that these components with their associated properties constitute successful elearning usability that result in usability attributes such as learnability, efficiency, memorability, error, and satisfaction.

Data were collected and analyzed using factor analysis with Varimax rotation. The results showed that the fundamental component, the appearance component, and the information presentation component explained for $26.978 \%, 20.630 \%$, and $19.629 \%$ of the variance in the collected data respectively.

The findings of this study revealed that all three components in the model were empirically validated to be reliable and interpretable among their associated factors. Specifically, the following statements were concluded:

1. The six usability properties of the fundamental component (simplicity, comfort, user friendly, control, navigability, and load time) in the model were empirically validated to be reliable and interpretable as items associated with this component.

2. The four usability properties of the appearance component (recognition, visual appearance, consistency, and well-organized) in the model were empirically validated to be reliable and interpretable as items associated with this component.

3. The four usability properties of the information presentation component (understandability, relevancy, 


\section{Issues in Information Systems}

Volume 15, Issue II, pp. 270-275, 2014

adequacy/task match, and right to the point) in the model were empirically validated to be reliable and interpretable as factors associated with the component.

The findings of this study support the e-learning usability courseware model's assertion that all components of the model, with their associated usability properties, are critical to the e-learning courseware usability. Therefore, this study recommends that the usability properties of the three components (fundamental, appearance, and information presentation) of the model advanced in this study be included in the design of e-learning courseware usability. The design of these usability properties influences the user learnability, efficiency, memorability, error, satisfaction, and other usability attributes, consequently impacting the learning. Furthermore, the findings of this study suggest that the instrument, driven from our model, can be used as a measurement tool to assess e-learning courseware usability. This study was limited to a sample of convenience from one higher education institution in the USA. Further research should focus on different population sample to improve the generalizability of the results.

\section{REFERENCES}

1. Allen, E. \& Seaman, J. (2014). Grade Change: Tracking Online Education in the United States. Retrieved December 10, 2012 from http://sloanconsortium.org/publications/survey/grade-change-2013

2. Caplan, S.H. (1994). Making usability a Kodak product differentiator. In: Wiklund, M.E. (Ed.), Usability in Practice. AP Professional, NY, pp. 21-58.

3. Dumas J., Redish J. (1993). A practical guide to usability testing, Norwood, NJ: Ablex

4. Guillemette R.A. (1989). Usability in computer documentation design: Conceptual and methodological considerations. IEEE Transactions on Professional Communication, 32, 217-228,

5. Holms M. (2002). Web usability \& navigation, New York: McGraw Hill.

6. ISO 9126 (1991). Software Product Evaluations- Quality characteristics and guidelines for their use, ISO DIS 9126.

7. ISO 9241 (1998). Ergonomics requirements for office work with visual display terminals (VDTs) - Part 11: Guidance on usability.

8. ISO/IEC 9126-1 (2001). Software engineering - Product quality -Part 1: Quality model.

9. Keinonen, T. (1998). One-dimensional usability - Influence of usability on consumers' product preference, Saarijärvi, Finland: Gummerus.

10. Koohang, A. (2004a). A study of users' perceptions toward e-learning courseware usability. International Journal on E-Learning, 3(2), 10-17.

11. Koohang, A. (2004b). Expanding the concept of usability. Informing Science Journal, 7, 129-141.

12. Koohang, A. \& du Plessis, J. (2004). Architecting Usability Properties in the E-Learning Instructional Design Process, International Journal on E-Learning, 3(30), 38-44.

13. Koohang, A. (2012). Active learning in e-learning: advancing a systemic model. Issues in Information Systems, 13(1), 68-76.

14. Nielsen J. (1993) Usability engineering. San Diego, CA: Academic Press.

15. Nielsen J. (2000). Designing web usability: The practice of simplicity, Indianapolis, IN: New Riders.

16. Quesenbery, W. (2003). Dimensions of usability. In Albers, M., \& Mazur, B., Content and complexity: Information design in technical communication. Mahwah, NJ: Lawrence Erbaum Associates.

17. Rosenbau, S. (1989). Usability evaluation vs. usability testing: When and why? IEEE Transactions of Professional Communication, 32, 210-216.

18. Rubin J. (1994). Handbook of usability testing. New York: John Wiley \& Sons.

19. Shackel B. (1991). Usability - context, framework, design and evaluation. In B. Shackel \& S. Richardson (eds.), Human factors for informatics usability, (pp. 21-38). Cambridge, UK: Cambridge University Press. 